\title{
Colorectal cancer in ulcerative colitis. Influence of anatomical extent and age at onset on colitis-cancer interval
}

\author{
A Sugita, D B Sachar, C Bodian, M B Ribeiro, A H Aufses Jr, A J Greenstein
}

\begin{abstract}
We have examined the age at onset of both ulcerative colitis and colitis-associated colorectal cancer in 100 patients seen at Mount Sinai Hospital between 1959 and 1988. There were 85 patients with extensive colitis and 15 with left sided colitis. There was a strong direct correlation between the age at onset of ulcerative colitis and age at diagnosis of cancer $(p<0.0001)$; this correlation was found both in patients with extensive colitis $(p<0.0001)$ and in those with left sided colitis $(p<0.005)$. Patients with left sided colitis developed both their colitis and their cancers about a decade later than did those with extensive disease, but the mean duration of colitis before diagnosis of cancer was virtually the same (about 21 years) in both groups, irrespective of the age at onset of disease.
\end{abstract}

Although colorectal cancer is a relatively rare complication of ulcerative colitis, ${ }^{12}$ the cancer incidence in patients with ulcerative colitis is higher than that in the general population. ${ }^{2}$ Suggested risk factors for the development of colitis-associated colorectal cancer include age at onset, duration, and anatomic extent of ulcerative colitis.

The relative importance of these factors remains controversial. The increasing use of surveillance programmes ${ }^{3-5}$ makes it even more critical that the factors associated with the increased colorectal cancer risk be clarified. Only if these factors are clearly defined can a rational and scientific approach to surveillance be proposed. We have examined these factors in 100 patients with colitis-associated colorectal cancer seen at Mount Sinai Hospital, for whom complete information was available.

Patients and methods

Retrospective review of the case records of all patients with ulcerative colitis admitted to Mount Sinai Hospital between January 1959 and March 1988 showed 102 patients with colorectal cancer. Two patients were excluded from our study. In one no information was available about the onset of ulcerative colitis, and in the other the extent of colitis could not be ascertained. The diagnosis of ulcerative colitis was made by clinical evaluation, barium enema, colonoscopy, and pathological examination of surgical specimen after colectomy. Other inflammatory bowel diseases such as Crohn's disease and infectious colitis were excluded. Left sided colitis was defined as disease starting distal to midtransverse colon, and extensive colitis as any disease beginning more proximal, by gross pathological examination of the colectomy specimen.

The three major factors recorded for each patient were age at onset of ulcerative colitis, age at diagnosis of colorectal cancer, and duration from onset of ulcerative colitis to diagnosis of colorectal cancer.

Linear regression analysis and Student's $t$ test were used for statistical analysis.

\section{Results}

Among the 100 patients with colorectal cancer, there were 85 with extensive colitis and 15 with left sided colitis. Age data on these patients are summarised in the Table.

Age at onset of ulcerative colitis (Fig 1). In all patients in the series the mean age at onset of ulcerative colitis was $27 \cdot 1$ years (median 26 years, range 1-56). The onset of left sided colitis occurred approximately a decade later (mean

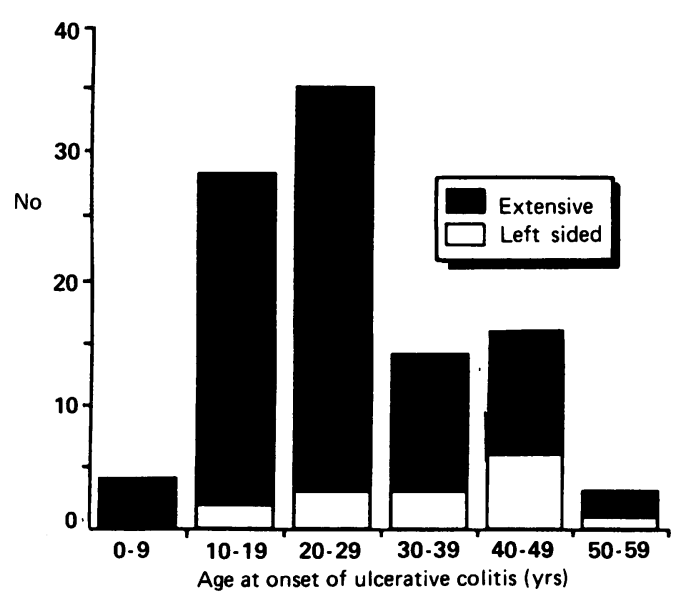

Figure 1: Age distribution at the onset of ulcerative colitis for patients with ulcerative colitis associated cancer. The onset of left sided colitis tended to be about a decade later than the onset of extensive colitis (mean $36 \cdot 7$ years $\mathrm{v} 25 \cdot 4$ years, $p<0 \cdot 0003$ ).

\begin{tabular}{|c|c|c|c|c|}
\hline & $\begin{array}{l}\text { All cases } \\
(n=100)\end{array}$ & $\begin{array}{l}\text { Universal colitis } \\
(n=85)\end{array}$ & $\begin{array}{l}\text { Left sided colitis } \\
(n=15)\end{array}$ & $\begin{array}{l}\text { Statistical } \\
\text { significance } \\
\text { (t test) }\end{array}$ \\
\hline $\begin{array}{l}\text { Age at onset of ulcerative colitis: } \\
\text { Mean (SD) } \\
\text { Median (range) }\end{array}$ & $\begin{array}{l}27 \cdot 1(11 \cdot 2) \\
26(1-56)\end{array}$ & $\begin{array}{l}25 \cdot 4(10 \cdot 7) \\
25(1-56)\end{array}$ & $\begin{array}{l}36 \cdot 7(12 \cdot 9) \\
39(17-56)\end{array}$ & $\mathrm{p}<0.0003$ \\
\hline $\begin{array}{l}\text { Mean (SD) } \\
\text { Median (range) }\end{array}$ & $\begin{array}{l}47 \cdot 7(13 \cdot 9) \\
48(19-77)\end{array}$ & $\begin{array}{l}45 \cdot 9(13 \cdot 4) \\
47(19-77)\end{array}$ & $\begin{array}{l}58 \cdot 3(12 \cdot 3) \\
56(40-76)\end{array}$ & $\mathrm{p}<0.0012$ \\
\hline $\begin{array}{l}\text { Duration from onset of ulcerative } \\
\text { colitis to diagnosis of cancer: }\end{array}$ & & & & \\
\hline $\begin{array}{l}\text { Mean (SD) } \\
\text { Median (range) }\end{array}$ & $\begin{array}{l}20 \cdot 7(9 \cdot 2) \\
20(5-46)\end{array}$ & $\begin{array}{l}20 \cdot 5(9 \cdot 1) \\
19(7-46)\end{array}$ & $\begin{array}{l}21 \cdot 5(9 \cdot 6) \\
22(5-40)\end{array}$ & $\begin{array}{l}\text { Not } \\
\text { significant }\end{array}$ \\
\hline
\end{tabular}




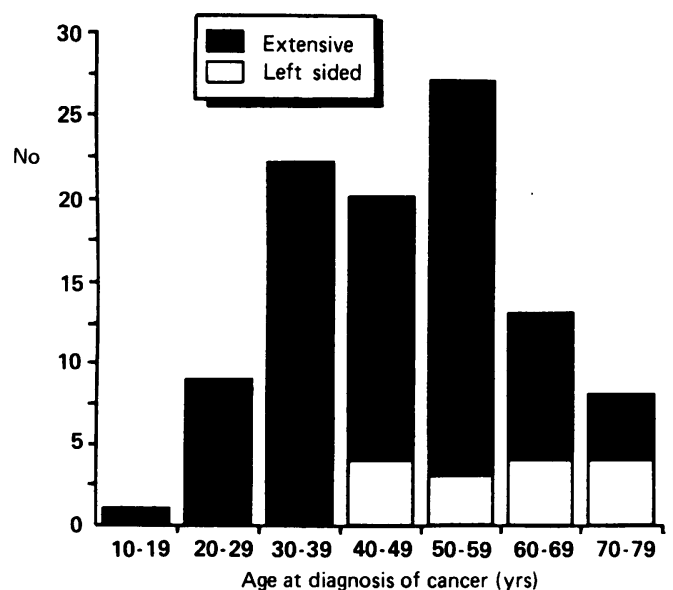

Figure 2: Age distribution at diagnosis of cancer for patients with ulcerative colitis-associated cancer. Cancers associated with left sided colitis tended to appear about a decade later than those associated with extensive colitis ( $58 \cdot 3$ years v 45.9 years, $p<0.0012$ ).

(SD) age 36.7 (12.9) years) than extensive disease $(25.4(10.7)$ years $(p<0.0003)$. In the largest group of extensive ulcerative colitis patients (38\%) onset was in the third decade, whereas the plurality $(40 \%)$ of left sided cases began in the fifth decade.

Age at diagnosis of colorectal cancer (Fig 2). In the total series the mean age at diagnosis of cancer was 47.7 years (median 48 years, range 19-77). Patients with left sided colitis developed
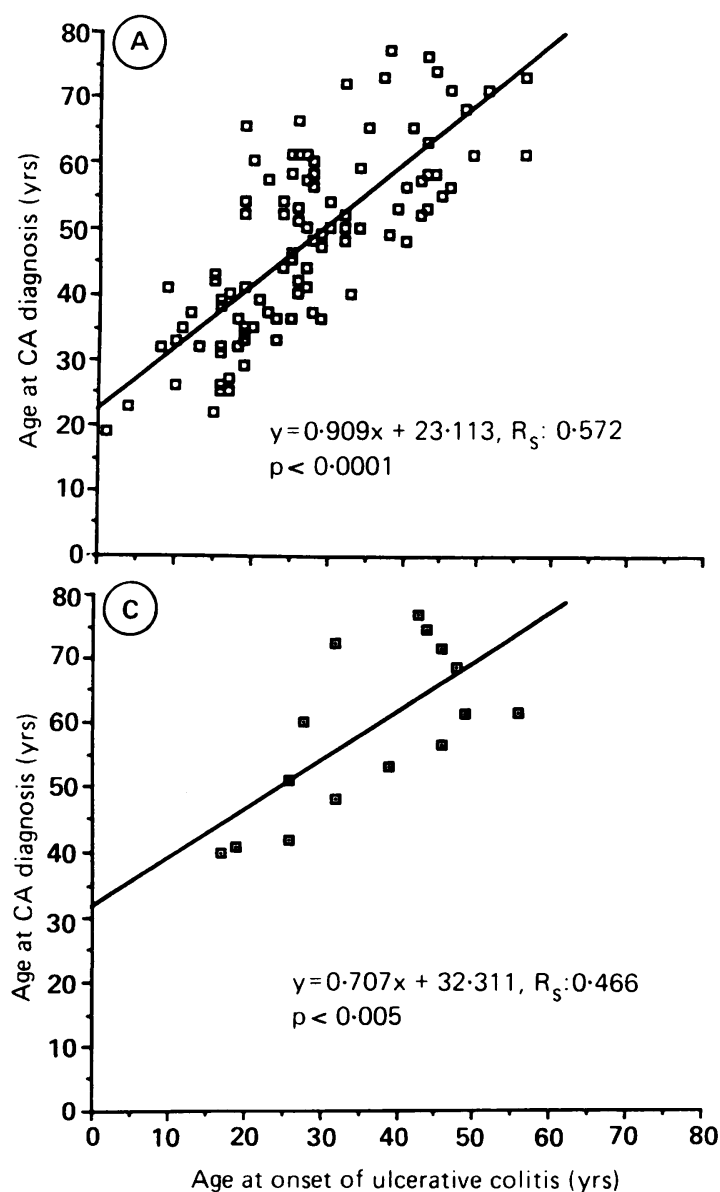

Figure 4: (A) Relation between age at onset of ulcerative colitis and age at diagnosis of cancer in all 100 patients in the series. There was a highly significant positive correlation $(p<0.0001) .(B)$ The relation between age at onset of ulcerative colitis and age at diagnosis of cancer in 85 patients with extensive colitis. There was a highly significant positive correlation $(p<0 \cdot 0001)$.

$(C)$ The relation between age at onset of ulcerative colitis and age at diagnosis of cancer in 15 patients with left sided colitis. There was a significant positive correlation $(p<0 \cdot 005)$.

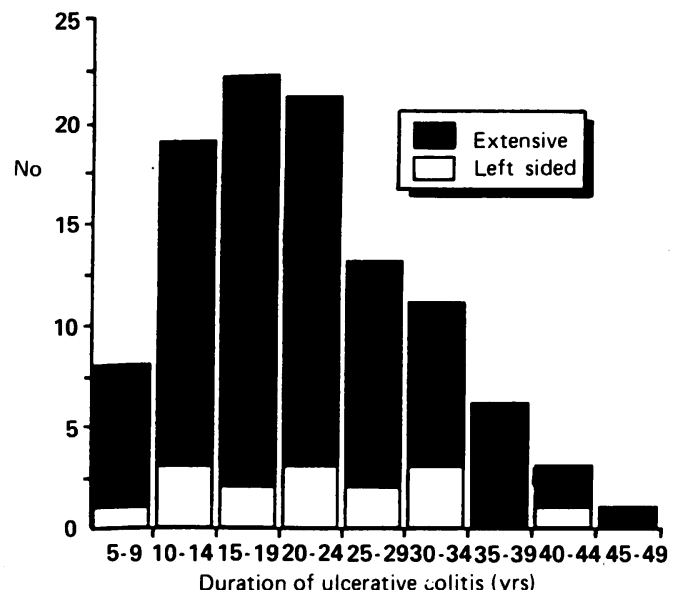

Figure 3: Duration from onset of ulcerative colitis to diagnosis of cancer. The distribution of colitis-cancer intervals was about the same, and the mean durations nearly identical, for both extensive and left sided colitis $(20 \cdot 5$ years $\mathrm{v} 21 \cdot 5$ years).

cancer approximately a decade later (mean (SD) $58.3(12 \cdot 3)$ years) than those with universal colitis (45.9 (13.4), $\mathrm{p}<0.0012)$. No patient with left sided colitis was found to have developed colorectal cancer within the first three decades of life, during which period $32 \%$ of all cancers associated with universal colitis were found.

Duration from onset of ulcerative colitis to diagnosis of colorectal cancer (Fig 3). The mean duration from onset to cancer in the overall series was $20 \cdot 7$

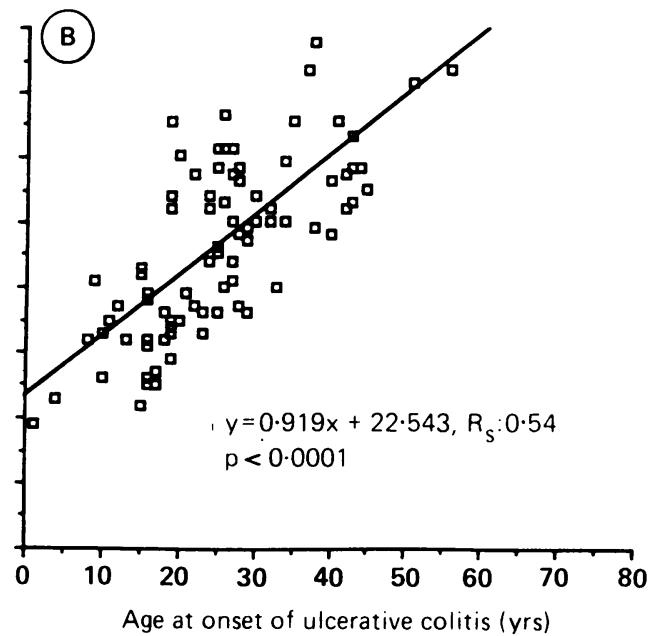


Figure 5: (A) The relation between age at onset of ulcerative colitis and disease duration in all 100 patients in this series. There was no significant correlation. (B) The relation between age at onset of ulcerative colitis and disease duration in the 85 patients with extensive colitis. There was no significant correlation. $(C)$ The relation between age at onset of ulcerative colitis and disease duration in the 15 patients with left sided colitis. There was no significant correlation.

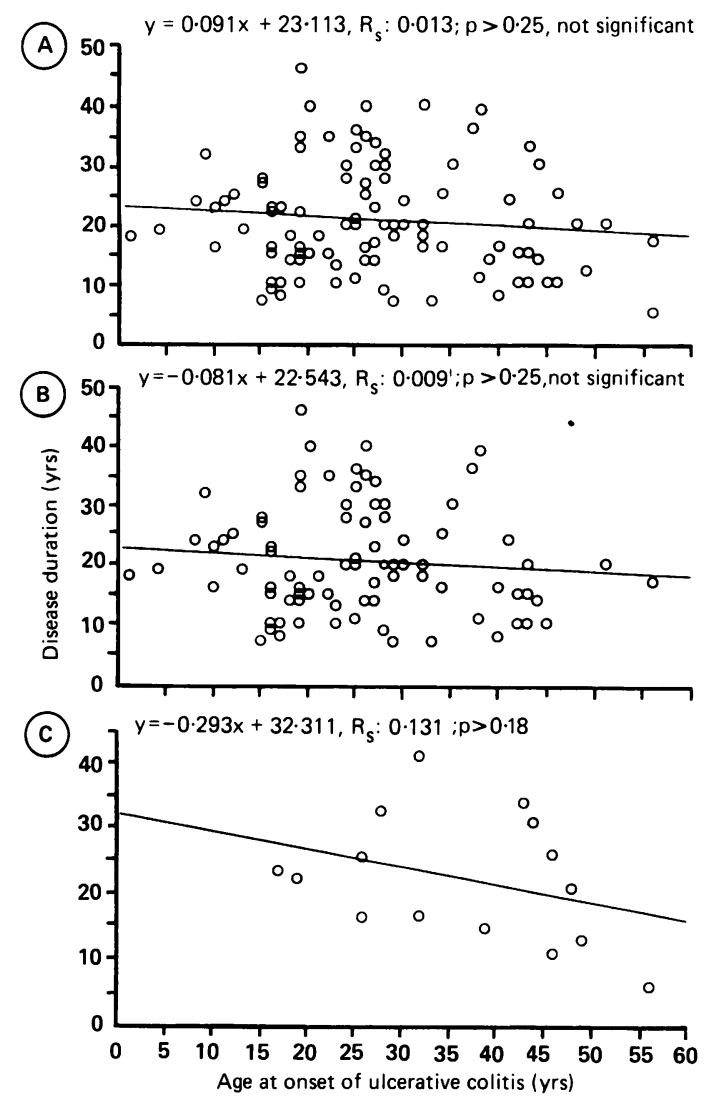

years (median 20 years, range 5-46). There was no significant difference in the mean duration from onset of ulcerative colitis to colorectal cancer between patients with universal colitis $(20.5(9 \cdot 1)$ years $)$ and those with left sided colitis $(21 \cdot 5(9 \cdot 6)$ years $)$.

Relation between the age at onset of ulcerative colitis and the age at diagnosis of cancer. The relation between age at onset of ulcerative colitis and age at diagnosis of cancer in each group was studied by regression analysis and is shown in Figure $4(\mathrm{~A}-\mathrm{C})$. A significant correlation was found between these two variables for the overall series (Fig 4(A), p $<0.0001$ ), as well as for patients with extensive colitis (Fig 4(B), $\mathrm{p}<0.0001$ ) and those with left sided colitis (Fig $4(\mathrm{C}), \mathrm{p}<0.005)$.

Relation between age at onset of ulcerative colitis and duration of colitis before diagnosis of cancer (Fig 5(A-C)). For both extensive and left sided colitis the intervals between onset of disease and diagnosis of cancer show little, if any, correlation with the ages at onset. There is a tendency for older patients to develop cancer after somewhat shorter disease durations than younger patients, as suggested by Gyde et al. ${ }^{6}$ This trend in our data, as in those of Gyde et al, might be due partly to the inevitably greater attrition among cases with an older age of onset than among cases with a younger age of onset throughout many decades of follow up. In any event, this slight difference in colitis-cancer intervals between older and younger onset patients does not even approach, much less achieve, statistical significance.

\section{Discussion}

This study has sought to clarify the respective roles of age at onset and total duration of ulcerative colitis in the development of colorectal cancer. Although it has been suggested ${ }^{7-10}$ that early age at onset might be a risk factor, our own studies $^{11}$ and others ${ }^{412}$ have indicated that an early age of onset does not seem to be an absolute risk factor independent of the longer disease duration and the wider anatomical extent that are more frequently associated with cases of childhood onset.

Recently, Kvist et $a l^{13}$ have published observations nearly identical to our own, indicating a straight line relation between age at onset of colitis and age at appearance of colorectal cancer, with similar time courses for both universal and left sided colitis

In a comprehensive multicentre study Gyde $e t$ $a l^{6}$ have challenged conventional wisdom by proposing that the development of cancer in extensive colitis is a genetic phenomenon independent of the total duration of disease, with cancers tending to emerge around age 50 regardless of the age at onset of the colitis. Perhaps their anomalous conclusion was influenced by their having excluded all cases of colitis with onset in childhood from their series. The present data, however, strongly reinforce the nearly unanimous consensus ${ }^{47911-16}$ that the development of cancer depends upon duration of colitis for extensive and left sided colitis alike.

We thank Mr Reuben Devaprasad for obtaining medical records and helping transfer data meticulously to Mcbee cards.

1 Farmer RG, Hawk WA, Turnbull RB. Carcinoma associated with mucosal ulcerative colitis and with transmural colitis and enteritis (Crohn's disease). Cancer 1971; 28: 289-92.

2 Butt JH, Lennard-Jones JE, Ritchie JK. A practical approach to the risk of cancer in inflammatory bowel disease. Med Clin to the risk of cancer in inflammat

3 Fuson JA, Farmer RG, Sullivan BH. Endoscopic surveillance for cancer in chronic ulcerative colitis. $\mathrm{Am} \mathcal{F}$ Gastroenterol 1980; 73: $120-6$.

4 Nugent FW, Haggit RC, Colcher H, Kutteruf GC. Malignant potential of chronic ulcerative colitis. Gastroenterology 1979 76: $1-5$.

5 Lennard-Jones JE. Cancer risk in ulcerative colitis: surveillance or surgery. Br F Surg 1985; 72 (suppl): S84-6.

6 Gyde SN, Prior P, Allan RN, et al. A cohort study of primary referrals from three centres. Gut 1988; 29: 206-17.

7 MacDougall IPM. The cancer risk in ulcerative colitis. Lancet 1964; ii: $655-8$.

8 Rosenqvist H, Ohrling H, Langercrantz R, Edling N. Ulcerative colitis and carcinoma coli. Lancet 1959; i: 906-8.

9 Edwards FC, Truelove SC. The course and prognosis of ulcerative colitis. Gut 1964; 5: 15-22.

10 Brostrom O, Lofberg R, Nordenvall B, Ost A, Hellers G. The risk of colorectal cancer in ulcerative colitis. An epidemiologic study. Scand f Gastroenterol 1987; 22: 1193-9.

11 Greenstein AJ, Sachar DB, Smith H, et al. Cancer in universal and left sided ulcerative colitis: factors determining risk. Gastroenterology 1979; 77 : 290-4.

12 Ekbom A, Hermich C, Zack M, Adams H-O. Ulcerative colitis and colorectal cancer: a population based study. N Engl

13 Kvist N, Jacobsen O, Kvist HK, et al. Malignancy in ulcerative colitis. Scand f Gastroenterol 1989; 24: 497-506.

14 Devroede GJ, Taylor WF, Sauer WG, Jackman RJ, Stickler GB. Cancer risk and life expectancy of children with GB. Cancer risk and life expectancy of child
ulcerative colitis. $N$ Engl f Med 1971; 285: 17-21.

15 Dennis C, Karlson KE. Cancer risk in ulcerative colitis: formidability per patient-year of late disease. Surgery 1961; 50: $568-71$.

16 Kewenter J, Ahlman H, Hulten L. Cancer risk in extensive ulcerative colitis. Ann Surg 1978; 188: 824-8. 